\title{
A Study on the Mediating Value of Self-efficacy in Primary and Secondary Education
}

\author{
Zhang Yan \\ College English Teaching Department of Zaozhuang University \\ Zaozhuang City, Shandong province, China
}

\begin{abstract}
Self-efficacy is a very important factor affecting primary and secondary education. On the basis of introducing the connotation of academic self-efficacy, this paper summarizes the conclusions about the relationship between self-efficacy and primary and secondary education, the mechanism of academic self-efficacy affecting academic achievement and related influencing factors in existing research, and the conclusions of primary and secondary education. The study of the mediating value of self-efficacy was discussed.
\end{abstract}

Keywords-mediating value; self-efficacy; primary and secondary education

\section{INTRODUCTION}

On the basis of the development of the teacher's knowledge structure, there will still be some questions in the practice of teaching activities. "The same kind of knowledge, taught by different teachers, why are there differences?" Positive reflects the importance of being a teacher's selfefficacy. The so-called teacher's self-efficacy is an intrinsic psychological experience and experience. It is the selfjudgment and belief of teachers on educational work and the educational ability to positively influence students' development. The same teacher, because of different aspects of self-efficacy, will show different levels of competence in different situations. On the other hand, the research also shows that a teacher has a positive self-perception of his professional identity, and will ignore the unpleasant feeling caused by poor working conditions. This shows that the teacher's professional identity will also affect the teacher's self-efficacy. sense.

\section{THE THEORETICAL SOURCE AND DEFINITION OF TEACHERS' SELF-EFFICACY}

The study of teachers' self-efficacy was first proposed by Amur and Berman, and its concept is theoretically derived from Bandura's concept of self-efficacy. Bandura believes that the type of individual thinking, the choice of behavior, effort and persistence, emotional stimulation and performance can have a direct or indirect impact on self-efficacy. Since then, many scholars have expanded and applied self-efficacy based on Bandura's self-efficacy theory, and proposed a more complete theoretical model and application concept in the field of educational psychology-teacher self-efficacy to explore teacher-to-personal teaching. Faith and judgment of ability. As a psychological variable, teacher self-efficacy cannot be directly measured and analyzed. It needs to be quantified and reflected by identification variables. There are also differences in the definition of the researcher, which can be divided into two types: teacher self-efficacy is a whole concept and a multi-dimensional concept.

The overall concept of the idea begins with Armor. Armor et al. interpret teacher self-efficacy as a belief in the teacher's own influence on student learning (Armor, 1976). Then (Berman \& Mc Laughlin, 1978) proposed in his research that teacher self-efficacy refers to the ability of teachers to judge students who have no interest or difficulty in dealing with their studies. Later, (P. Ashton, 1984) and others considered that teacher self-efficacy refers to teachers' beliefs and expectations that individuals can influence students. (Newmann, Rutter, \& Smith, 1989), from the perspective of organizational role, defines teacher self-efficacy as: a teacher's perception of whether teaching can enhance student achievement, and it is a judgment of teachers' ability to guide students to learn successfully. Reflects the extent to which teachers invest in teaching.

The multidimensional concept is represented by Bandura himself. He defines teacher self-efficacy as the belief and judgment of teachers in the teaching situation and their ability to counter the external environment's negative impact on students in the teaching activities (Bandura, , \& Lin Ying), 2001). He believes that self-efficacy is a performance belief that involves many different aspects of teaching work, and includes two components: outcome expectations and performance expectations.

The above-mentioned researchers' inconsistencies in the definition of concepts can be seen in the following: (1) is an ability that encourages teachers to believe that they can help students solve various learning problems no matter what the circumstances. (2) It is a belief that it will keep teachers steadfast in their belief that they can overcome obstacles and guide students to positive learning. This belief reflects the teacher's subjectivity, enthusiasm and creativity in teaching activities; (3) is a perception, reflection on his own teaching practice, and thinking about whether he can arouse students to learn and obtain a sense of personal satisfaction. (4) is a dynamic process that changes with the acquisition of new information. Self-efficacy will produce enough efforts to succeed, and successful outcomes will further strengthen the expectations of self-success. 


\section{THE CONNOTATION AND CHARACTERISTICS OF TEACHERS' SELF-EFFICACY}

Starting from Bandura's theory of social learning, it believes that efficacy is mainly developed through four sources of information (mastery experience, alternative experience, social persuasion, physical and emotional state), and the regulation of individual behavior is manifested in its Affect people's choice of activities and environmental choices. Summarizing the existing research, the connotation of teachers' self-efficacy has the following three aspects: Firstly, the concept of teacher self-efficacy is multi-faceted, which contains both general teaching efficacy and personal teaching efficacy; including cognitive components. It is the teacher's judgment on his own teaching level, and also includes the emotional component, which is the professional emotion that teachers experience in the education industry. Secondly, teacher self-efficacy is the teacher's belief in whether he can successfully educate students. Thirdly, the teacher's selfefficacy is not only the teacher's general educational efficacy, but also broadly includes the self-efficacy that can be involved in many aspects of education.

Some scholars have pointed out that teachers' self-efficacy has the following three characteristics: subjective characteristics, implicit features, stability and situational coexistence, consistency and inconsistency (Hong Xiumin \& Pang Lijuan), 2006), this is mainly reflected in the teacher's subjectiveness in the evaluation of their work ability and personal education ability, and this self-efficacy exists in the teacher's belief in a potential way, and affects the teacher's educational behavior, at a certain time. This kind of performance will remain at a relatively stable level, but this is not absolutely static, it will change with the specific situation, and because the individual has a self-affirmation and consistent psychological tendency. Self-efficacy tends to be consistent when engaging in educational work in different subjects. There are many factors influencing teachers' selfefficacy. For example, teachers' own factors include growth environment, gender, age, teaching age, values, self-awareness, direct experience, and types of teaching subjects. External factors include school differences, social environmental impacts, and students. As well as family influences, changes in these factors will make them manifest inconsistencies.

\section{A RELATED STUDY ON THE MEDIATING ROLE OF SELF- EFFICACY}

Previous studies have focused on the study between two variables, and paid less attention to its intrinsic influence mechanism. This is an important focus of research in this study. This study finds that self-efficacy is in conditional knowledge through hierarchical regression. It plays a full intermediary role in the relationship with professional identity. This shows that conditional knowledge plays a predictive role in professional identity through the intermediary effect of selfefficacy. Because the previous studies did not have empirical research between the three, it is impossible to make a comparative analysis of the results of this study. But the results are consistent with Denham \& Michael's point of view (teacher self-efficacy is a mediator in a variety of variables that influence teachers' perceptions of teaching behavior and student performance). In addition, in the literature analysis of teachers' self-efficacy, it is found that self-efficacy can be divided into two components (Gibson \& Dembo, 1984). One is the expectation of results, which means that an individual may have a certain behavior for himself. The subjective judgment of the results, good results will make the behavior activated and selected; this can be used to indicate that the teacher expects his or her educational behavior to be successful and effective, and will adjust the behavior of his own behavior, and will choose to activate those that are beneficial to The resulting behaviors, such as exploring new teaching methods, interacting with students in a timely manner, and constantly replenishing their own knowledge systems. The second is the performance expectation, which refers to the individual's belief in his ability to successfully perform the actions that have been activated and selected. Whether it can complete its behavior is mainly controlled by the desired performance. As a teacher, when he is convinced that he has the ability to conduct educational activities, he will have a high degree of self-efficacy and can actually implement the activities. That is to say, teachers with good knowledge structure and high self-efficacy can better promote their educational activities and obtain the success of education. In this practical process of successful acquisition, their professional identity will be gradually improved. Professional recognition

It will also be more conducive to teachers' further educational behavior. The empirical study of the study shows that the teacher's knowledge structure can predict the professional identity well under the influence of self-efficacy. This also provides a theoretical basis for our teacher training, and hopes to provide various training for teachers. Among them, we can pay attention to the cultivation of teachers' knowledge system and self-efficacy.

\section{DECISIONS AND FORECASTS OF ACADEMIC SELF- EFFICACY AND ACADEMIC ACHIEVEMENT}

Almost all of the research supports the conclusion that academic self-efficacy is closely related to academic achievement. The researchers believe that the level of academic self-efficacy plays a decisive role in academic achievement and can be used as academic achievement. One of the predictors.

Bandura pointed out that self-efficacy is better than individual skills. Bandura accurately predicts students' intellectual performance. Zajacova et al. also showed that the self-efficacy scale is more stable and consistent with students' academic success than the anxiety scale. In the study, Liew et al. trained students in the first grade to improve their selfefficacy. They found that students' self-efficacy and academic performance improved in the second and third grades, and the positive impact on reading performance was particularly significant. . More powerful evidence that self-efficacy can predict academic achievement comes from meta-analysis of others. The researchers analyzed the results of academic selfefficacy published by Multon in 1977 to 1988 36. The results of the analysis were: the correlation coefficient between selfefficacy and academic achievement is, some academics 0.38 $14 \%$ Variations in grades can be attributed to self-efficacy. 
John et al. used a self-contained self-efficacy questionnaire to confirm the results of this meta-analysis-the overall selfefficacy predictions were fairly stable. The results of the regression analysis showed that the level of self-efficacy 13 weeks ago still explained the current academic performance. Variation in grades.

Researchers believe that academic self-efficacy is able to determine and predict academic achievement because students with high self-efficacy in school have more motivation to engage in challenging learning tasks and set higher for themselves. The achievement goals of the academic achievement will put more effort and persistence into accomplishing these goals. In the academic situation, they have more positive attitudes and emotions and less anxiety. For students of any level, those with high self-efficacy are more likely to succeed in learning activities and more effective learning strategies; students with low self-efficacy tend to choose simple tasks and are afraid to set more High goals make it easy to exaggerate the arduous task. When encountering difficulties, it is easier to escape and retreat. It is easier to experience anxiety than students with high selfefficacy, and it is difficult to apply effective learning strategies in time.

\section{THE MECHANISM OF ACADEMIC SELF-EFFICACY} AFFECTING ACADEMIC ACHIEVEMENT: INTERMEDIARY ROLE

According to the social cognitive theory in the theory of self-efficacy Bandura, self-efficacy is the individual's ability belief in the behavior of one's own behavior. This belief controls the subject's viewpoint and action to a certain extent, thus affecting the result of behavior- This means that many factors that influence behavior and its effects are driven by self-efficacy. A considerable number of studies have also shown that academic self-efficacy is an intermediary of other factors and has an impact on academic achievement. The main research conclusions are:

Academic self-efficacy is an intermediary between ability, previous academic performance, and academic achievement. A survey of 329 middle school students in Pajares conducted a path analysis method to find that the ability and previous academic performance indirectly influenced the subsequent academic performance through mediation.

Academic self-efficacy is the intermediary between selfregulating skills and academic achievement. Others also used path analysis Zimmerman's method to confirm this relationship. Their research shows that even with selfregulating skills, if there is no firm self-efficacy to ensure selfregulation, then in difficult situations, the impact of selfregulation on academic achievement will be reduced.

Academic self-efficacy is the intermediary between achievement motivation and academic achievement. And Pintrich DeGroot conducted a survey and survey of 173 11th grade middle school students with self-efficacy, knowledge values, test anxiety, etc. After analysis, they believed that selfefficacy plays an intermediary or "helper" in cognitive activities. "It can enhance the use of strategies and improve academic achievement." Lent et al also found that selfefficacy not only stimulates students' motivational level, maintains students' endurance in the learning process, but also cultivates students' intrinsic interest in each subject, and transforms learning from passive knowledge acceptance process to active one. The process of seeking knowledge.

Academic self-efficacy is the intermediary between academic anxiety and academic achievement. Tian Bao and Guo Dejun constructed a structural equation model of test anxiety affecting test scores with integrated thinking, and measured the academic self-efficacy and test anxiety level of Minggao 265 middle school students. The results showed that test anxiety passed the test self-efficacy. A mediator variable has an impact on test scores.

Of course, not all studies have reached the same conclusion, and some studies have shown that these factors directly affect academic achievement and do not have a mediating effect on self-efficacy. But the fact that there is a close connection between academic self-efficacy and academic achievement, whether it is an intermediary or not, is unquestionable.

\section{FACTORS INFLUENCING ACADEMIC SELF-EFFICACY IN ACADEMIC ACHIEVEMENT}

Whether academic self-efficacy affects academic achievement and the extent of its effects is influenced by many factors. Some researchers have explored these factors.

Bandura believes that participants' familiarity with the task will affect the predictive power of Bandura's self-efficacy. Complex learning tasks place higher demands on participants knowledge, cognitive ability, behavioral skills, physical and mental endeavor, operational proficiency, perseverance, etc., so those who lack experience with complex tasks are likely to be difficult to perform these tasks. In this case, the predictive power of self-efficacy is likely to decrease. In addition, when the task is more complicated, it is difficult for people to grasp the task more accurately, and the individual may overestimate or underestimate the difficulty of the task. Overestimating the task requirements makes people tend to keep it, and underestimating the task requirements makes people overconfident. Both of these situations affect the accuracy of self-efficacy for task prediction.

In addition, people often do not fully understand the difficulty of new and more complex tasks. When assessing the difficulty of a task, people often rely on the success rate of others who have engaged in the activity. However, external information is often unstable, and individual estimates of task difficulty will change. This change in estimates in turn affects an individual's effectiveness assessment, which in turn affects individual behavior. In this case, self-efficacy makes it difficult to accurately assess academic performance, and the predictive power of self-efficacy will diminish.

Success in a simple learning task is expected for the individual and therefore does not cause any reassessment of self-efficacy. It is easier for people to judge learning tasks and to determine more accurately whether they are qualified for these tasks. Therefore, the predictive power of self-efficacy at this time is stronger. 
Some researchers believe that the time interval between performance beliefs and academic performance is another factor that affects the efficacy. Because learning behavior is regulated by the performance beliefs that are learned during learning, rather than by previously held performance beliefs, the longer the time interval, the weaker the predictive power of self-efficacy, unless performance is effective during this period. Faith remains the same; on the contrary, when performance beliefs and academic performance are close in time, the relationship between the two can be revealed relatively accurately by measurement.

However, Kent et al. found that the effect of self-efficacy on behavioral outcomes was weaker over time, especially strong self-efficacy predicting coping behavior after five years and health function after four years. It can be seen that it does not make much sense to simply look at the amount of time. The key is whether the performance belief has changed over time. The stability of efficacy beliefs is determined by factors such as the mode of acquisition, intensity, level, and the nature of experience. Specifically, people with weak self-efficacy, when difficult tasks come, they are likely to have self-doubt, leading to a further reduction in self-efficacy, thus affecting the effectiveness of predictions; students with high performance can dare to challenge, difficult tasks The impact on the level of self-efficacy is limited, and the predictive power of self-efficacy is also relatively stable.

Bandura believes that due to the differences between different areas of activity, the skills and skills required vary widely. A person's sense of self-efficacy is different in different fields. Therefore, there is no general sense of selfefficacy. Anytime discussing self-efficacy refers to the sense of self-efficacy associated with a particular field. In general, individuals tend to choose environments that they feel can be effective, while avoiding environments that are beyond their control. Therefore, the "general" academic self-efficacy does not predict the academic achievement of a particular field or discipline. Pajares and Miller explored the predictive power of performance beliefs and found that performance beliefs are better predictive under better matching conditions than under partially matched conditions. It can be seen that the matching of self-efficacy test and academic achievement test content will directly affect the effectiveness of prediction.

\section{CONCLUSION}

Foreign studies on academic self-efficacy mainly focus on two aspects: one is to explore the relationship between efficacy and related psychological structure, academic motivation and academic achievement; the second is to explore the sense of self-efficacy before college students enter college. The impact of professional choice and future career choices. Among them, the second field has a very important role in the theory and practice of consulting psychology and professional psychology. Because it touches the two environments of school and society, it can examine the impact of academic self-efficacy on individual development from a broader and broader field, and it has far-reaching significance. This requires domestic researchers to broaden existing research areas and explore the utility and value of academic self-efficacy in a comprehensive and in-depth manner.

\section{ACKNOWLEDGEMENT}

Mid-term Research Achievements of Applied Research of Zaozhuang Social Science Federation: Study on the Mediating Role of Self-efficacy in Primary and Secondary Education in Zaozhuang City LX2019134.

\section{REFERENCES}

[1] Li Dongbin, Yan Hongda. Personality traits, general self-efficacy and their relationship among key teachers in middle school. Psychology, 2010(1): 63

[2] Zhu Miaoxian et al. Research on the relationship between self-efficacy and personality traits of young teachers in primary schools. Journal of Zibo Teachers College, 2010(3): 9.

[3] Zhang Jinghuan, Zhao Chengfu, Li Dongmei. Research on the concept of primary school teachers' creativity training. Educational Research, 2004, 3: 85-89.

[4] Chen Yu. The status quo of primary school teachers' creativity training and creative classroom teaching behavior. Master's thesis of Shandong Normal University, 2005.

[5] Chu Yuxia. The relationship between primary school teachers' achievement goal orientation, creative teaching efficacy and creativity. Master's thesis of Shandong Normal University, 2008. 